\title{
Computed Tomography analysis of damage in composites subjected to impact loading
}

\author{
V. Crupi, G. Epasto, E. Guglielmino \\ Department of Industrial Chemistry and Materials Engineering, University of Messina, Contrada di Dio, 98166 Messina - Italy \\ vcrupi@ingegneria.unime.it; gepasto@ingegneria.unime.it; eguglie@ingegneria.unime.it
}

\begin{abstract}
The composites, used in the transportation engineering, include different classes with a wide range of materials and properties within each type.

The following different typologies of composites have been investigated: laminated composites, PVC foam sandwiches, aluminium foam and honeycomb sandwiches.

Aim of this paper was the analysis of low-velocity impact response of such composites and the investigation of their collapse modes.

Low velocity impact tests were carried out by a drop test machine in order to investigate and compare their structural response in terms of energy absorption capacity.

The failure mode and the internal damage of the impacted composites have been, also, investigated using 3D Computed Tomography.
\end{abstract}

KeYwords. Composites; Low velocity impact; Computed Tomography; Impact damage; Collapse modes; Transportation engineering.

\section{INTRODUCTION}

$\checkmark$ he structures realized using sandwich technologies combine low weight with high energy absorbing capacity, so they are suitable for applications in the transport industry (automotive, aerospace, shipbuilding industry), where the "lightweight design" philosophy and the safety of vehicles are very important aspects.

While sandwich structures with polymeric foams have been applied for many years, currently there is a considerable and growing interest in the use of sandwiches with aluminium foam core [1, 2] and with honeycomb core [3].

Composite structures are more susceptible to impact damage than a similar metallic structure, because impacts create internal damages, that often are undetectable by a simple visual inspection and this is a great problem in the real structures. This internal damage can cause drastic strength reduction and can grow under applied loads. For these reasons, the impact strength has been a factor in limiting the use of composite materials. Impact behaviour of sandwich structures is completely different from that of metals and composite monolithic laminates and is dominated by the deformation of the core [4], which gets crushed as transverse stresses become large. Impacts can induce damage to the skins, the core and the core-skins interface. Core deformation and failure are decisive factors for the energy absorption capacity of sandwich structures. With aluminium honeycomb cores, damage consists of crushing or "buckling" of cell walls in a region surrounding the impact point, while, in foam cores, damage looks more like a crack for low-energy impacts [4].

For these reasons, it is necessary to acquire a better understanding of their behaviour and collapse modes under impact loads. 
An extensive series of experimental tests were performed in order to obtain the mechanical characterization of aluminium foams under static and dynamic loading conditions [5]. Hazizan et al. [6] carried out low velocity impact tests in order to investigate the response of sandwiches, made of aluminium honeycomb core and glass fibre reinforced/epoxy skins. Compston et al. [7] compared the low velocity impact behaviour of aluminium foam and polymeric foam sandwiches and different damage modes were observed: the polymeric foam sandwiches exhibited localized damage (skin fracture and core crushing) with negligible permanent out-of plane strain, whereas the aluminium foam sandwiches experienced little fracture with extensive permanent out-of plane strain. Moreover the post impact characterization tests showed that the aluminium foam specimens exhibited lower strain, suggesting a better damage tolerance respect to the polymeric foam sandwiches.

In a previous research paper of the authors [8], the structural response of aluminium foam sandwiches under static and impact loading was compared with that of the PVC foam sandwiches.

Aim of the present research was the investigation and the comparison of the structural response of laminated and sandwich (with polymeric and aluminium core) panels under impact loading.

The failure mode and the damaged structure of the impacted composites have been investigated by an X-ray computed tomography (CT) system, that allows a three-dimensional reconstruction of the analyzed object.

X-ray CT improves the use of X-ray radiography by imaging detailed cross-sectional views of the specimens, thereby resolving through-thickness delamination and matrix cracks. Cone-beam CT is a three dimensional imaging technique which is used non-destructively to inspect the inner structure of an object by transmission measurements using X-rays. A large number of projection images are obtained by rotating the sample. After a reconstruction process, the volume rendering of the external and internal geometries of the part is created. CT is a very useful tool to identify structural inhomogeneities, voids, fractures, microcracks and porous structures in both metallic and polymeric composites where there is a significant difference in density. This non-invasive technique has been used to characterize quantitatively the microstructure and the internal architecture of different typologies of closed-cell aluminium alloy foam [9] and to obtain the data for finite element models of open-cell aluminium foam specimens [10]. Schilling et al. [11] demonstrated that the $C T$ system can detect the damage and internal flaws, including delamination and microcraking, in fibre-reinforced polymeric matrix composites. Laminated composites, stitched with varying stitch densities and stitch thread thickness, were subjected to low-velocity impact tests at different energy values and the impact damages were investigated using an X-ray micro-computed tomography, that was able to show detailed through-thickness matrix cracks distribution and 3D delamination damage pattern [12]. It was noted that a CT image alone provided much better resolution of the outline of the damage area than the planar view of X-radiography [13].

\section{MATERIALS AND METHODS}

\section{Materials}

]

$\mathrm{n}$ this paper, the following different typologies of composites have been investigated (Fig 1): laminated composites, PVC foam core sandwiches, aluminium foam sandwiches (AFS) and aluminium honeycomb sandwiches.

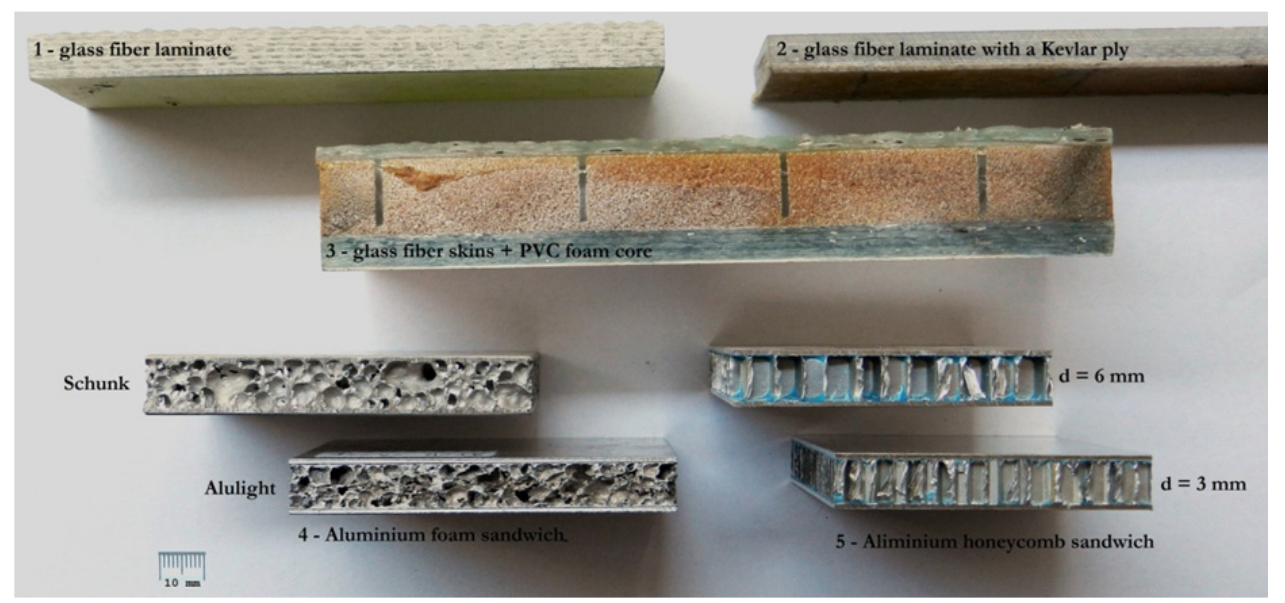

Figure 1: Investigated composite materials. 
The polymeric sandwiches consist of a PVC foam core and two GFRP (glass-fibre reinforced plastic) laminated skins. The measured total density is about $0.68 \mathrm{~g} / \mathrm{cm}^{3}$. The PVC foam core has a density of $0.075 \mathrm{~g} / \mathrm{cm}^{3}$ and a thickness of about 15 $\mathrm{mm}$, while the average thickness is $3 \mathrm{~mm}$ for the upper skin and $7 \mathrm{~mm}$ for the lower one.

One of the two investigated laminates is made of alternated fibre-glass MAT and GFRP $\left[0^{\circ} / 90^{\circ}\right]$ biaxial layers and has a thickness of about $10 \mathrm{~mm}$, the other one has an additional $\left[0^{\circ} / 90^{\circ}\right]$ Kevlar reinforced layer and two GFRP [ $\left.\pm 45^{\circ}\right]$ biaxial layers and a thickness of about $9 \mathrm{~mm}$.

All of these typologies of composite materials (sandwiches and laminates) are commonly used for yacht structures.

Two different commercial aluminium alloy foam sandwiches have been investigated. The first one (Schunk GmbH, Heuchelheim, Germany), consists of an AlSi7 foam core and two AlMn1 faces obtained by extrusion (integral skins), the second one (Alulight GmbH, Ranshofen, Austria) is made of an AlSi10 core and two $\mathrm{Al}(99.5 \%)$ faces, bonded to the core by an epoxy adhesive. The measured total density is $0.87 \mathrm{~g} / \mathrm{cm}^{3}$ for AFS Schunk and $0.95 \mathrm{~g} / \mathrm{cm}^{3}$ for AFS Alulight, while the core density, calculated by assuming a density of $2.73 \mathrm{~g} / \mathrm{cm}^{3}$ for the aluminium skins and a face thickness of $1 \mathrm{~mm}$, is 0.45 $\mathrm{g} / \mathrm{cm}^{3}$ for AFS Schunk and $0.53 \mathrm{~g} / \mathrm{cm}^{3}$ for AFS Alulight.

The following aluminium honeycomb sandwiches typologies were, also, investigated: 1/8-5052-0.0020 and 1/4-50520.0025; the designation corresponds to cell size (inch) - alloy - foil thickness (inch). The first typology consists of hexagonal cells with diameter of $3 \mathrm{~mm}$ and thickness of $0.05 \mathrm{~mm}$ and has a honeycomb density equal to about $130 \mathrm{~kg} / \mathrm{m}^{3}$, the second one has hexagonal cells with diameter of $6 \mathrm{~mm}$ and thickness of $0.06 \mathrm{~mm}$ and has a honeycomb density equal to about $80 \mathrm{~kg} / \mathrm{m}^{3}$. The honeycomb core is made of AA5052 aluminium alloy and the two skins are realized by AA5754 H32 aluminium alloy. The skin thickness is about $1 \mathrm{~mm}$.

\section{Methods}

Low-velocity impact tests were performed using a CEAST Fractovis Plus drop-weight impact test machine (Fig. 2). The instrumented impactor, having a hemispherical tip with diameter of $20 \mathrm{~mm}$, hit the centre of the specimens.

The tests were conducted on the different typologies of composites with an impactor mass of about $7 \mathrm{~kg}$. The drop height was adjusted to generate different level of initial impact energies (from 56 to $284 \mathrm{~J}$ ), each with a corresponding impact velocity (from 4 to $9 \mathrm{~m} / \mathrm{s}$ ). The specimens were clamped by a rigid metallic plate with a diameter of $40 \mathrm{~mm}$, as shown in Fig. 2, without crushing the sample.

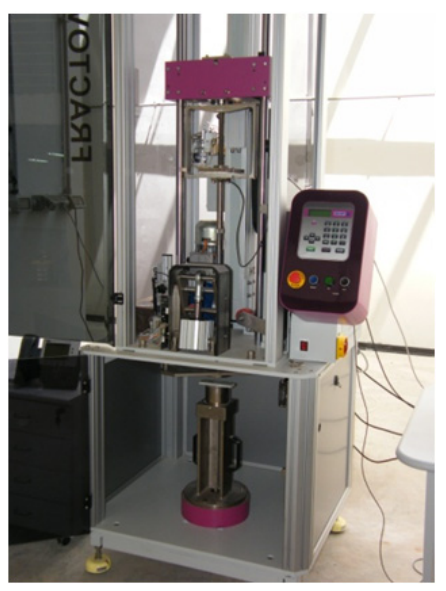

(a)

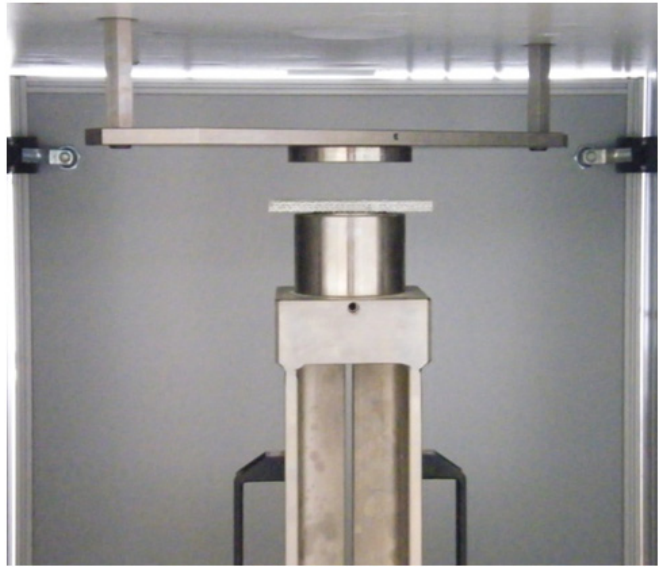

(b)

Figure 2: a) Drop-weight impact test machine; b) Clamping system.

The impact damage of the composites, undetectable by a visual inspection, was analyzed by the Y.CT Vario focus X-ray computed tomography system (Fig. 3). This unit is equipped with an X-ray source having maximum voltage and current of $225 \mathrm{kV}$ and $7.1 \mathrm{~mA}$, respectively, depending on the focal spot size that can be chosen among these values: $250 \mu \mathrm{m}, 300$ $\mu \mathrm{m}, 500 \mu \mathrm{m}$ and $800 \mu \mathrm{m}$. The detector system is a flat panel with a resolution of $1920 \mathrm{x} 1536$ pixels. The scans, reported in this paper, were conducted with $250 \mu \mathrm{m}$ focus and X-rays were set at a voltage of $210 \mathrm{kV}$ and at a current of about 1.1 $\mathrm{mA}$. Different filters ( $\mathrm{Al}, \mathrm{Cu}$ and $\mathrm{Sn}$ filters) were used depending on the sample. It is worth noting that the sourcedetector and the source-sample distances are critical in determining the magnification of the sample and, thus, the resolution of the scan: the closer the sample was to the source and the further away from the detector, the higher the magnification. A conical X-ray beam scanned the sample, which was rotated at increments of $0.5^{\circ} / \mathrm{s}$ for each rotation 
step. This procedure was then repeated until a full rotation of $360^{\circ}$ was achieved, and a total of 1440 projections were then obtained to be used in the 3D profile generation. The sizes of the voxels and images were $0.033 \div 0.050 \mathrm{~mm}$ and 2048 x 2048 pixels respectively. The integration time was chosen equal to $500 \mathrm{~ms}$. It is important to underline that this NDT technique doesn't require to cut and polish the samples for carrying out the X-ray measurements. This allows a significant savings of time and the investigation of the internal damage without perturbing the impacted specimen.

The system, based on a variable focal-spot size technology, creates the cross-sectional images of three-dimensional objects using X-rays. A volumetric representation of the item to be inspected is obtained as a result of the CT. Both the material inner and outer structures and the geometric dimensions of the item to be inspected are recognizable.

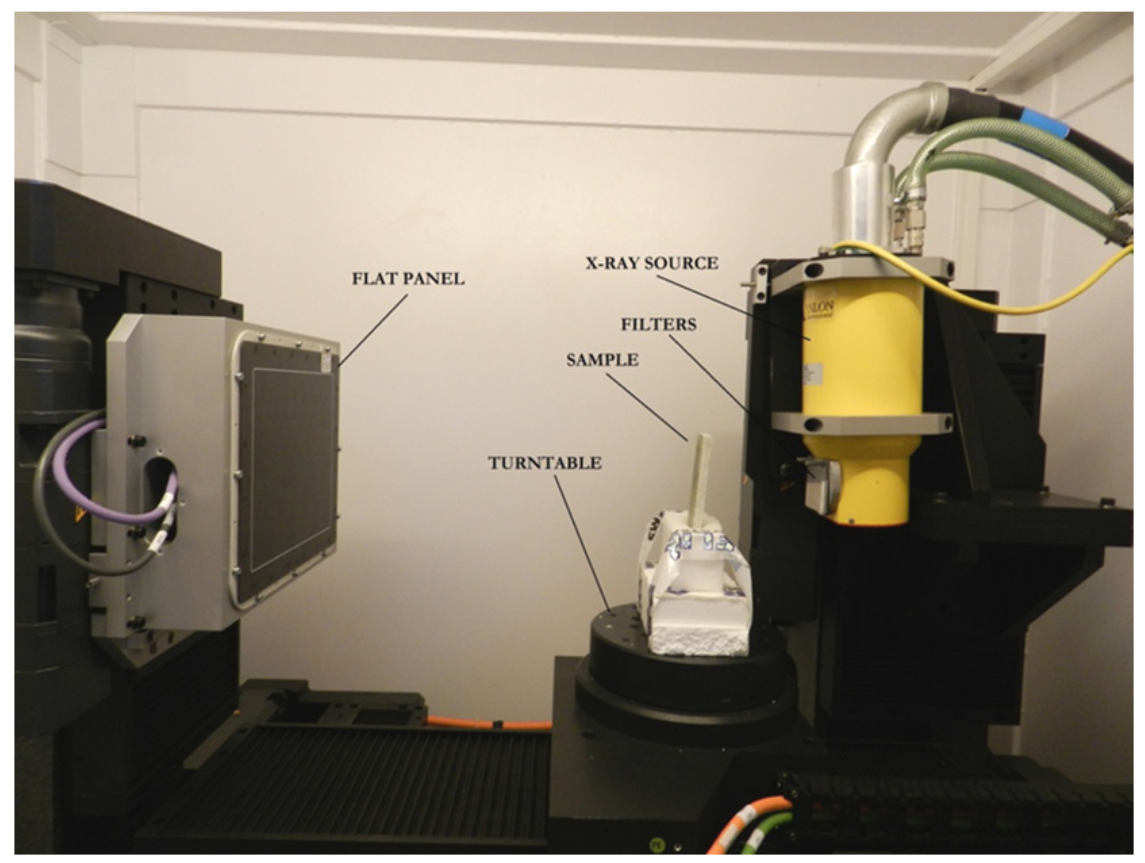

Figure 3: Y.CT V ario cone-beam X-ray tomography system.

\section{RESULTS AND DISCUSSION}

\section{Analysis of investigated composites using CT}

he 3D reconstruction of an aluminium honeycomb panel with $3 \mathrm{~mm}$ cell size was obtained by means of the CT as shown in Fig. 4. The cell sizes can be measured by CT system; as example the analysis in terms of grey levels intensity, along the middle line, drawn on the sample middle section, is reported in Fig. 4.

The investigation of the aluminium foams by means of CT is very useful to check their quality in terms of porosity distribution, that influence the mechanical properties of the foams. Fig. 5 shows the CT reconstruction of an AFS Schunk panel; the tomogram allows the investigation of the foam porosity and the localization and quantification of the pores by checking the grey levels intensity. Because of the non homogeneity of the AFS panels, it is strongly necessary to check the sample before carrying out the impact test and to discard defective samples, as the one shown in Fig. 5.

CT analyses allowed, also, the investigation of a polymeric sandwich with glass-fibre reinforced skins and foam core for quality control of flaws and for the evaluation of thickness and geometric properties of core and skin layers (Fig. 6).

The thickness and the typology of each laminate layer can be evaluated by CT, the dimensions of a biaxial ply of a GFRP laminated composite, obtained by checking the greyscale levels, are shown in Fig. 7.

\section{Energy absorption and collapse modes of the composites under impact loading}

The low-velocity impact tests produced the complete failure of the GFRP laminated composite at an initial impact velocity of $8 \mathrm{~m} / \mathrm{s}$ with an energy absorption of about $217 \mathrm{~J}$, whereas a test at $\mathrm{v}=9 \mathrm{~m} / \mathrm{s}$ was necessary for the failure of the hybrid Kevlar/fiber-glass laminate, confirming the higher impact strength of Kevlar fiber composites than that of GFRP. 


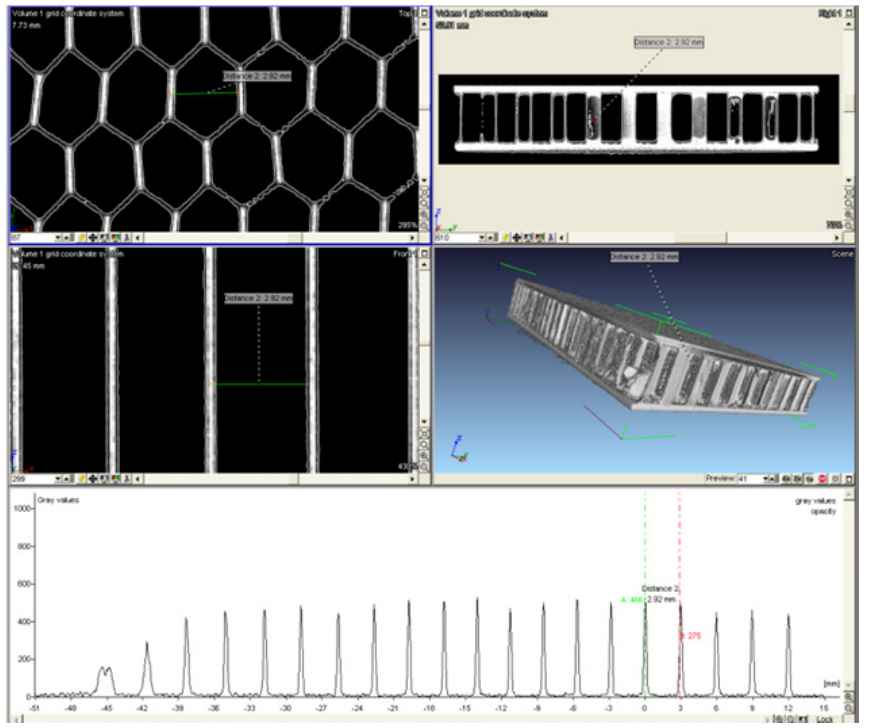

Figure 4: CT analysis of an honeycomb panel $(d=3 \mathrm{~mm})$.

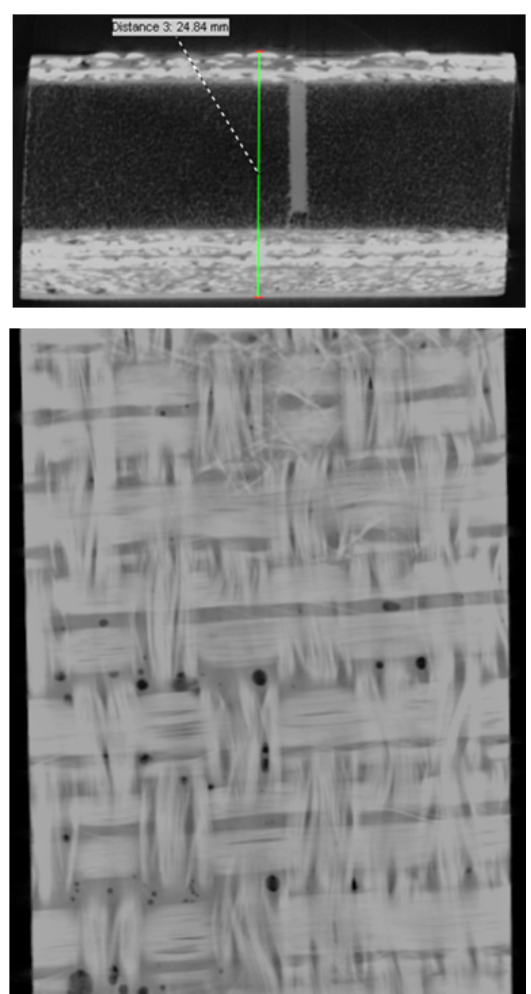

Figure 6: CT analysis of a polymeric sandwich composite.

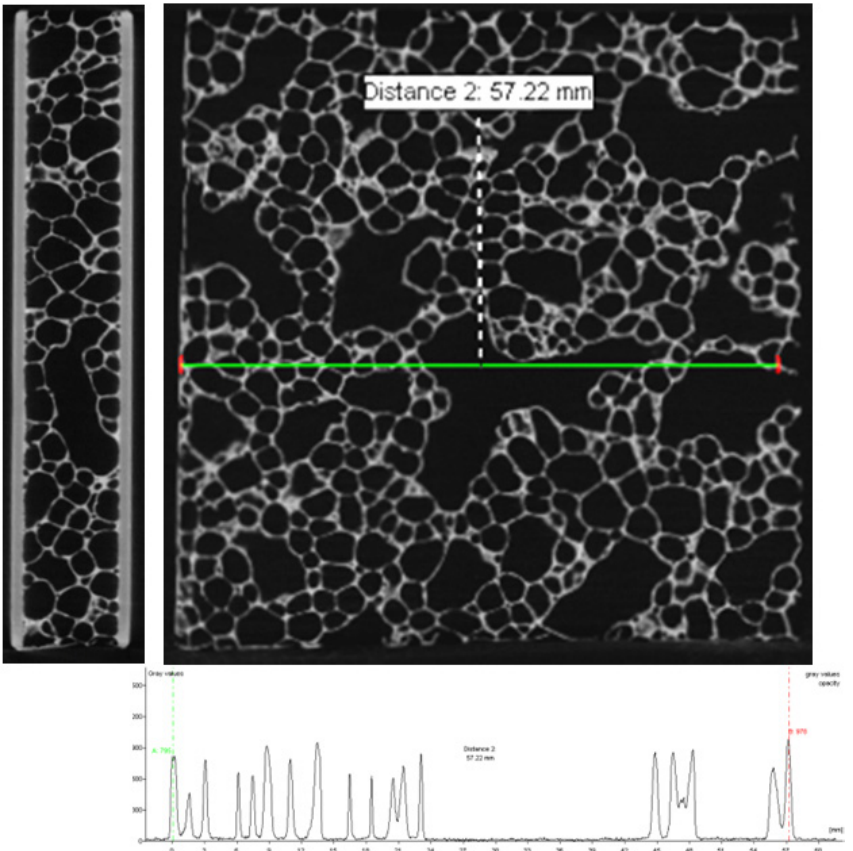

Figure 5: CT analysis of an AFS Schunk panel.
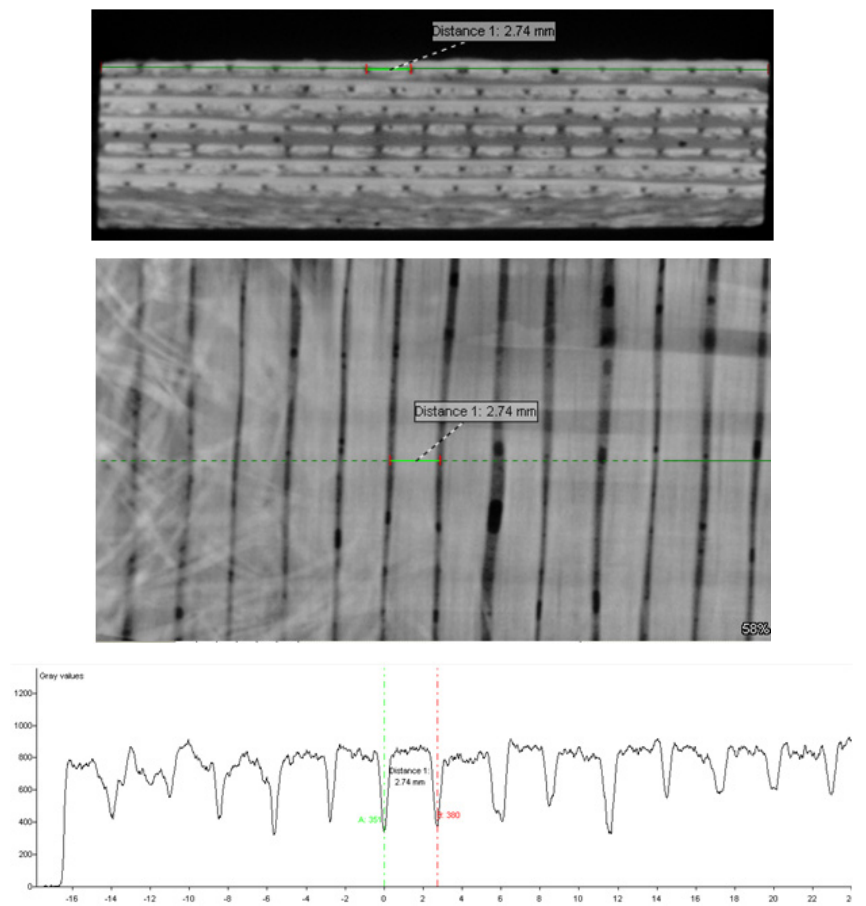

Figure 7: CT analysis of a laminated composite.

The impact damage mechanisms of composites with Kevlar fiber layers are distinctly different from those of GFRP. X-ray CT images of two laminated specimens subjected to $126 \mathrm{~J}$ impact energy are shown in Fig. 8. In particular, the images show a comparison between a fiber-glass laminated composite (upper images of Fig. 8) and a hybrid Kevlar/fiber-glass 
laminated composite (lower images of Fig. 8). The cross-sectional images of the impact-damaged area were taken in the frontal through-thickness direction of the specimen, considering a distance between two slices of about $0.4 \mathrm{~mm}$. Only the most representative slices of the two damaged specimens are shown in Fig. 8.

In the hybrid Kevlar/fiber-glass laminate the impact damage mechanism is dominated by failure of mat and biaxial fiberglass layers, whereas $\left[0^{\circ} / 90^{\circ}\right]$ Kevlar layer, positioned near the bottom face, don't fail completely, but show out-ofplain deformation. That is confirmed by the tomogram of the middle section of an impacted laminate after a test at $\mathrm{v}=8$ $\mathrm{m} / \mathrm{s}$, shown in Fig. 9, where shear cracks are also observed.
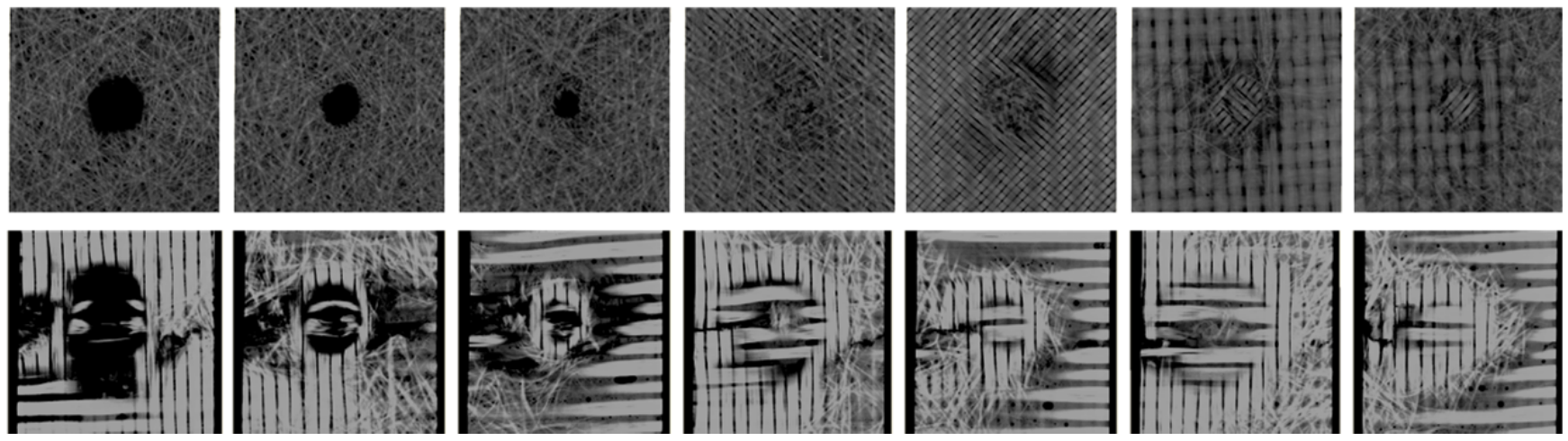

Figure 8: Tomograms of laminated specimens impacted at energy of $126 \mathrm{~J}$.

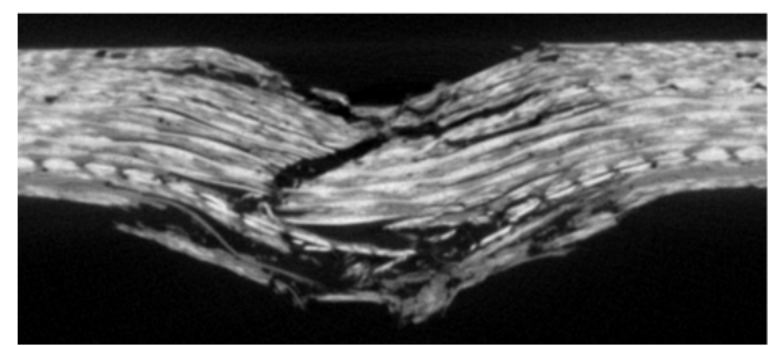

Figure 9: Tomogram of an hybrid Kevlar/fiber-glass laminate after the impact $(\mathrm{v}=8 \mathrm{~m} / \mathrm{s})$.

Fig. 10 shows that damage mechanism of a GFRP laminate after the impact at $6 \mathrm{~m} / \mathrm{s}$ is characterized by delamination and fiber/matrix debonding. Three major damages can be found through the thickness: broken fibers, delaminations and transverse matrix cracks (Figs. 8 and 11). As described by Abrate [4], the damage process is initiated by matrix cracks which then induce delaminations, that is the debonding between adjacent laminas. Shear cracks, positioned at an angle from the midsurface, were observed in the tomogram of Fig. 11a relative to the middle section of impacted panel, confirming the important contribute of the shear stresses. In the low-velocity impact tests, the matrix cracks appeared in the first layer impacted because of the high, localized contact stresses and damage propagated through the thickness towards the bottom face, resulting in a pine tree pattern $[4,12]$ as shown in Fig. 11a. Large delamination damage occurs at the back face and progressively becomes smaller toward the impact face (Fig. 11b). The matrix cracking and fiber breakage were easily detected by a visual inspection as the near surface matrix cracking manifested itself in a stresswhitened or discolored patch, as reported in literature [14]. The longitudinal matrix interlaminar cracks below the impacted surface and the presence of delaminations at the bottom of the specimen can be noted in the tomograms of Fig. 11 relative to different transverse sections of the impacted specimens.

In the low-velocity impact tests performed on the polymeric sandwiches, the first impacted skin is the $3 \mathrm{~mm}$ thick one. The tests, carried out at impact velocity values lower than $9 \mathrm{~m} / \mathrm{s}$, did not produce the complete failure of the specimens; the impactor penetrated only the upper skin and the core. The complete failure with the perforation of the lower skin, occurred only after the impact test at $\mathrm{v}=9 \mathrm{~m} / \mathrm{s}$ and the energy amount, required to produce the complete failure, was evaluated to be $263 \mathrm{~J}$. The post-impact specimens showed a localized damage and very little out of plane displacement.

The CT investigations of the impacted polymeric sandwiches allow a better understanding of their failure mode, which is characterized by the rapid crushing of the PVC core (Figs. 12 - 14). Careful observation of the failure sequences in these specimens at various impact energies showed that the failure was produced by the formation of matrix cracks in the central region of the skin under the impactor (Fig. 12) and, for tests at higher impact energy, the cracks propagated along 
the adhesive/face interface, which resulted in core fracture (Fig. 13), failure of vertical reinforcements and delamination of the lower skin, as shown in Fig. 14.

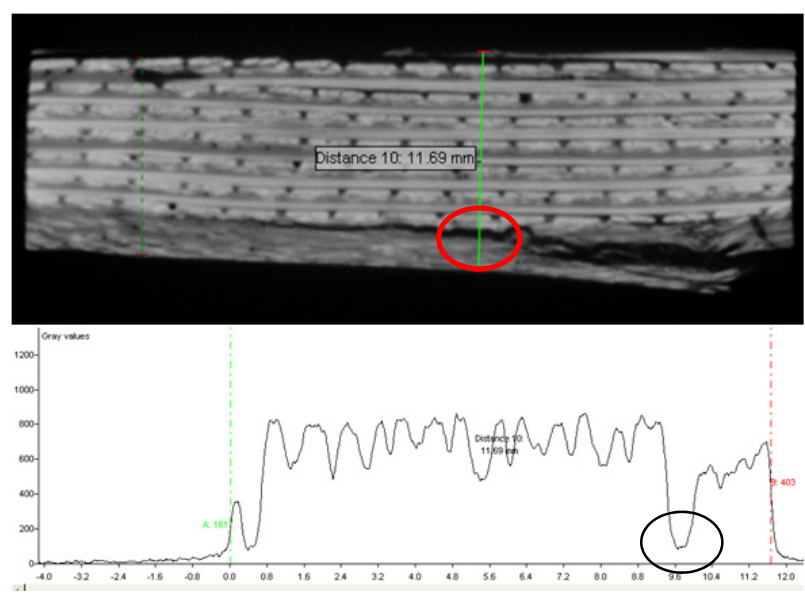

Figure 10: Tomograms of a GFRP laminated panel after the impact $(\mathrm{v}=6 \mathrm{~m} / \mathrm{s})$.

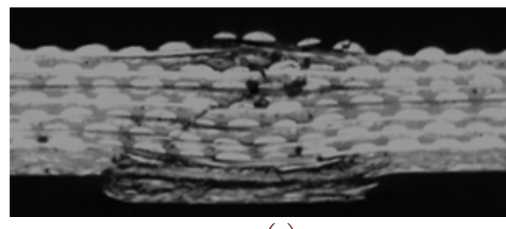

(a)

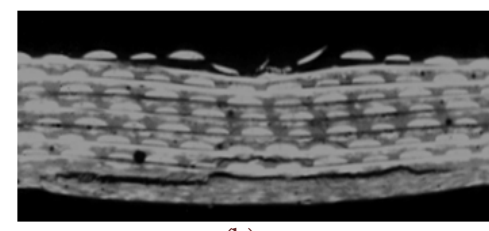

(b)

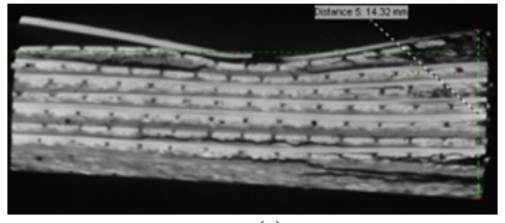

(c)

Figure 11: Tomograms of a GFRP laminated panel after the impact $(\mathrm{v}=6 \mathrm{~m} / \mathrm{s})$.

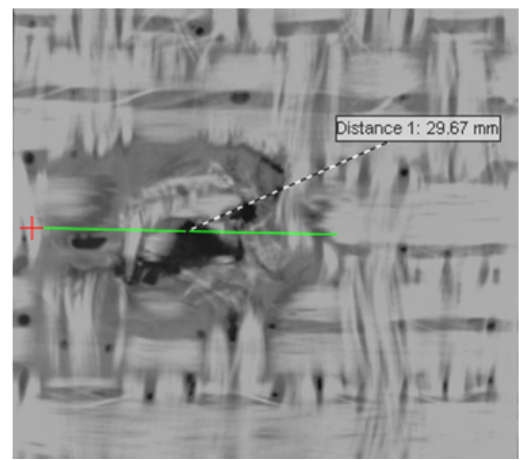

(a)

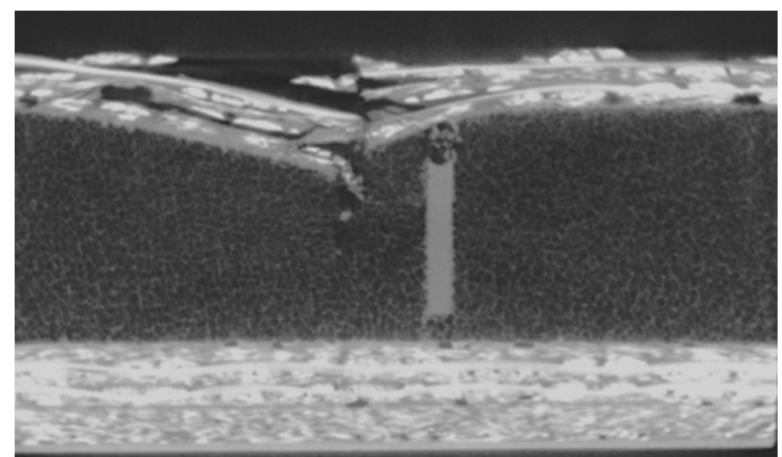

(b)

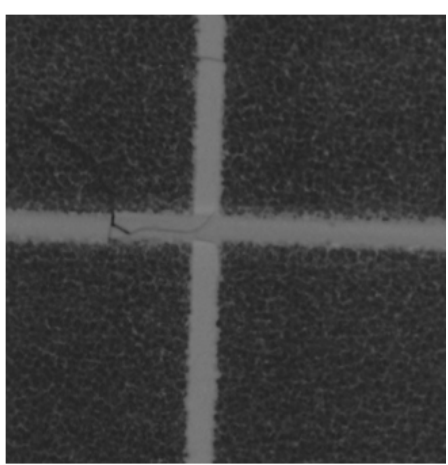

(c)

Figure 12: Tomographic images of the damaged GFRP-PVC foam core panel after the impact $(\mathrm{v}=4 \mathrm{~m} / \mathrm{s})$.

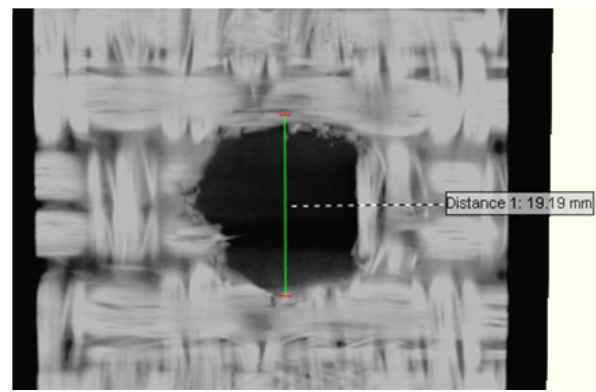

(a)

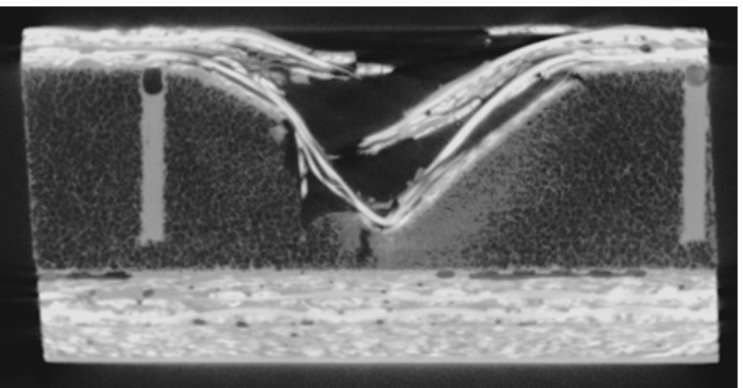

(b)

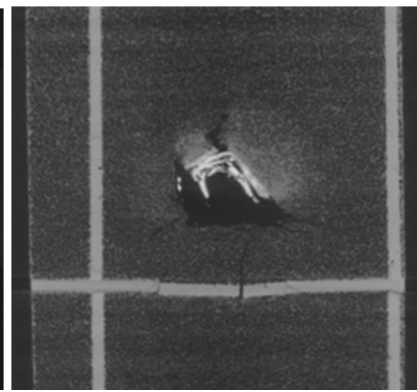

(c)

Figure 13: Tomographic images of the damaged GFRP-PVC foam core panel after the impact $(\mathrm{v}=6 \mathrm{~m} / \mathrm{s})$. 


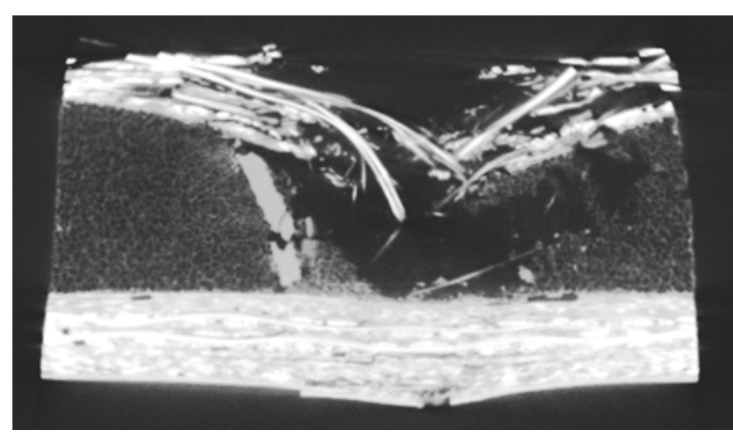

(a)
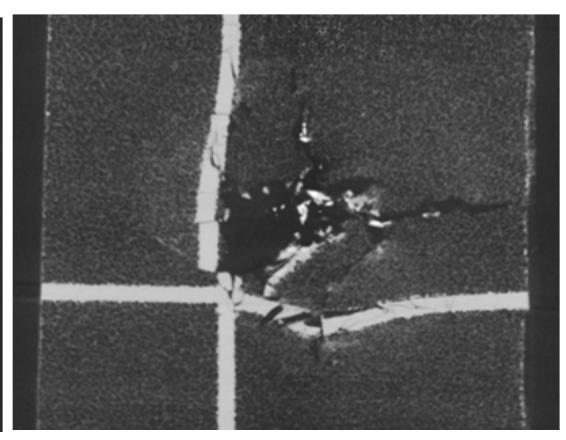

(b)

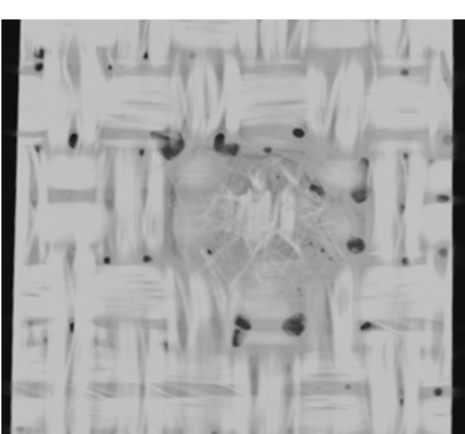

(c)

Figure 14: Tomograms of GFRP-PVC foam core panel after the impact ( $\mathrm{v}=7 \mathrm{~m} / \mathrm{s})$; the ply in $(\mathrm{c})$ is on the lower skin of the sample.

For that concerns the two AFS typologies (Schunk and Alulight), the complete failure of the specimens (foam core thickness $9 \mathrm{~mm}$ and skin thickness $1 \mathrm{~mm}$ ) occurred after the impact tests at $\mathrm{v}=7$ and $8 \mathrm{~m} / \mathrm{s}$. Their impact behaviour is different respect to the polymeric sandwiches; the AFS experienced some foam cell crushing and extensive out-of-plane displacement even at low impact energy. The capacity of energy absorption is strongly influenced by the foam quality, that resulted to be better for the AFS Alulight panels, that require an energy amount of $142 \mathrm{~J}$ for the complete failure with the rupture of the lower skin, whereas for the AFS Schunk panels it is sufficient an energy value of $122 \mathrm{~J}$. The data scattering, observed in the tests, is due to the different porosity distributions of the aluminium foams, so it is important to check the foam quality by means of non-destructive techniques, such as the CT.

Figs. 15 and 16 show the tomographic images just for AFS Alulight and Schunk panels after the impact at v $=2$ and $4 \mathrm{~m} / \mathrm{s}$. These tomographic images allow a better understanding of their failure mode, that is characterized by the progressive crushing of the foam cells with a more uniform distribution of the impacted load.

The post-impact investigation of the specimens confirms the results of the tests conducted by Compston et al. [7]: the AFS specimens experienced extensive ductile fracture with large out-of-plane displacement compared to the impact behaviour of the polymeric sandwiches and laminates. Moreover, the AFS structures are relatively intact compared to the more catastrophic and localized fracture of the polymeric sandwiches, so they exhibit a better post-impact damage tolerance and mechanical properties.

Low velocity impact tests were performed, also, on honeycomb panels (core thickness $9 \mathrm{~mm}$ and skin thickness $1 \mathrm{~mm}$ ). The experimental results confirm, as expected, that the honeycomb cells of smaller size $(d=3 \mathrm{~mm})$ are able to absorb greater amounts of energy at a given impact velocity and require an energy value of $128 \mathrm{~J}$ for the complete failure respect to the $116 \mathrm{~J}$ necessary for the failure of panels with larger cells $(d=6 \mathrm{~mm})$.

The collapse of the honeycomb sandwich occurs for the initial deformation of the upper skin and for the buckling of the core cells as confirmed by the CT investigations (Fig. 17). The specimens experienced ductile fracture with out-of-plane displacement. The analysis of the tomographic images (Fig. 17) of the panels with smaller cells $(d=3 \mathrm{~mm})$ reveals that the collapse of the cells is located in the area concerned by the impact, while the rest of the structure remains almost intact. Instead, with the same initial energy of impact, the collapse of the panels with larger cells $(d=6 \mathrm{~mm})$ affects almost all cells.
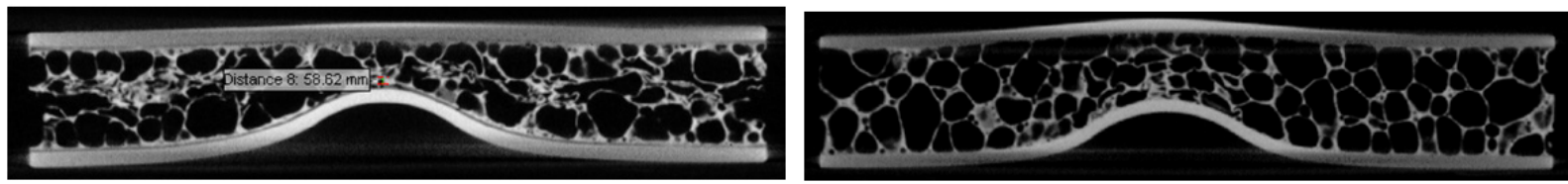

Figure 15: Tomographic images of the damaged $A F S$ panels (left Alulight, right Schunk) after the impact $(\mathrm{v}=2 \mathrm{~m} / \mathrm{s})$.
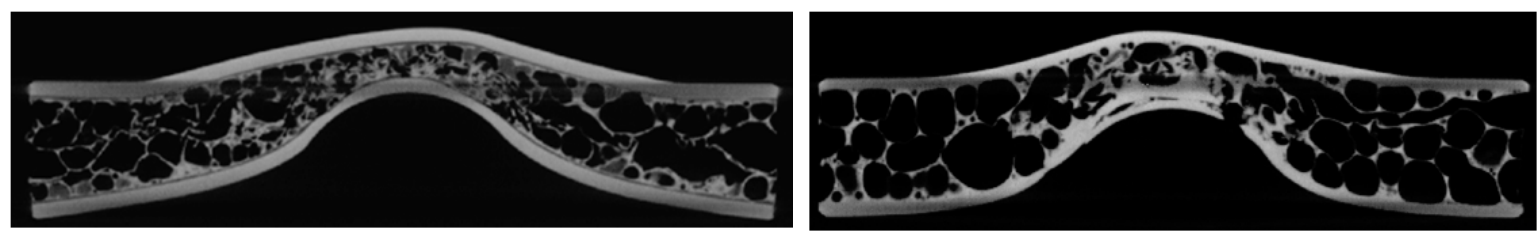

Figure 16: Tomographic images of the damaged $A F S$ panels (left $A$ lulight, right $S$ chunk) after the impact $(\mathrm{v}=4 \mathrm{~m} / \mathrm{s})$. 

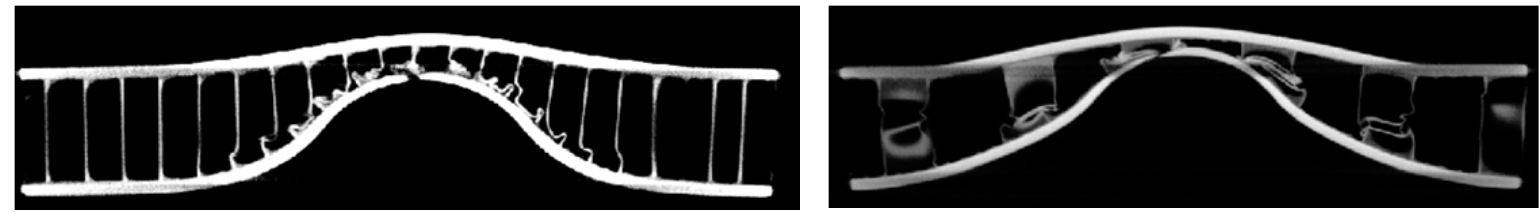

Figure 17: Tomographic images of the damaged honeycomb core panels after the impact $(d=3$ and $6 \mathrm{~mm}, \mathrm{v}=4 \mathrm{~m} / \mathrm{s})$.

The values of energy required to produce the complete failure of the investigated composites are reported in Fig. 18.

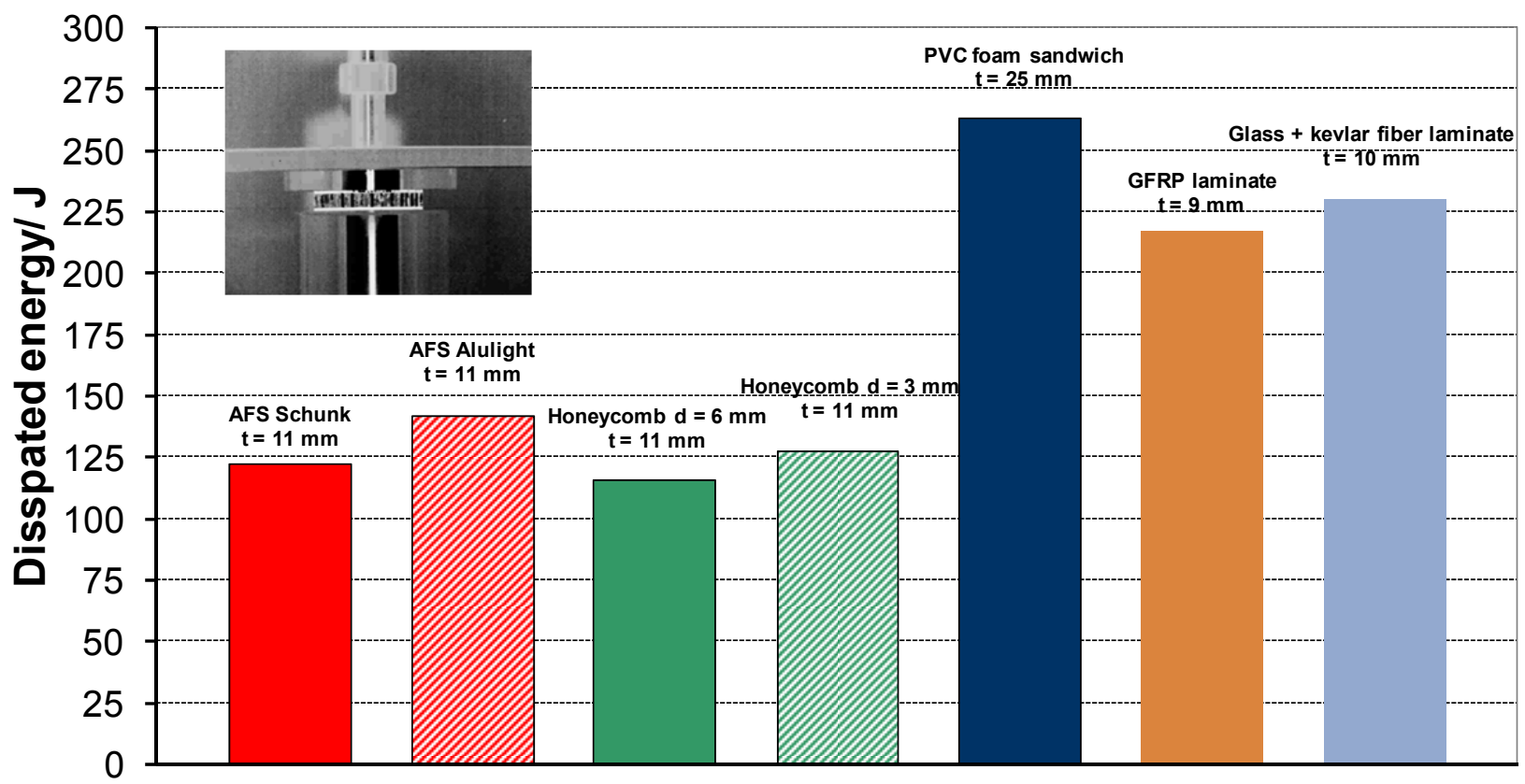

Figure 18: Energy required to produce complete failure of the investigated composites.

\section{CONCLUSIONS}

$\mathrm{C}$ omposite materials, especially in the form of sandwich structures, with their combinations of low weight and high energy absorbing capacity are very attractive for applications that require lightweight structures, such as the transport industry, where problems of collision and crash have increased in the last years. This study experimentally investigates the impact behaviour of different typologies of composites, comparing their impact response in terms of energy absorption and failure mode.

Low velocity impact tests were carried out on the following typologies of composites: laminated composites, PVC foam sandwiches, aluminium foam and honeycomb sandwiches. The test results confirm that the Kevlar fibre reinforced layers had, as expected, good impact performance and that the PVC foam sandwiches, which have an higher thickness, required an higher energy amount to produce the complete failure with respect to the laminates and aluminium sandwiches, but different failure modes were observed during the tests.

An advanced non-destructive technique like X-ray tomography was used to investigate the failure mode and the damage of the composites subjected to impact loading by means of the analysis of cross-sectional views.

The aluminium sandwiches experienced ductile fracture with large out-of-plane displacement compared to the failure mode of the laminates and PVC foam sandwiches and this makes the damage detection procedure easier. Moreover, their structures are relatively intact compared to the more catastrophic and localized fracture of the polymeric composites and, in consequence, they exhibit a better post-impact strength. 
The collapse of honeycomb sandwiches occurred for the buckling of the cells and is strongly influenced by the cell size, whereas the AFS collapsed for the foam crushing and their energy absorbing capacity depends by the foam quality, so the $C T$ investigation is very useful to check their porosity distribution.

For laminated composites, local contact stresses produced matrix cracks on the first impacted layer and the damage propagated through the thickness downward by a succession of intra-ply cracks and interface delaminations, producing the so called pine tree pattern.

\section{REFERENCES}

[1] J. Baumeister, J. Banhart, M. Weber, Materials \& Design, 18 (4) (1997) 217.

[2] J. Banhart, C. Schmoll, U. Neumann, In: Proc. Conf. Materials in Oceanic Environment (Euromat '98), Editor: L. Faria, 1 (1998) 55.

[3] K.B. Shin, J.Y. Lee, S.H. Cho, Composite Structures, 84 (3) (2008) 228.

[4] S. Abrate, Impact on Composite Structures, Edited by Cambridge University Press (2005).

[5] L. Peroni, M. Avalle, M. Peroni, International Journal of Impact Engineering, 35 (2008) 644

[6] M.A. Hazizan, W.J. Cantwell, Composite: Part B, 34 (2003) 679.

[7] P. Compston, M. Styles, S. Kalyanasundaram, Journal of Sandwich Structures and Materials, 8 (2006) 365.

[8] V. Crupi, G. Epasto, E. Guglielmino, Journal of Sandwich Structures and Materials, (2011) doi:10.1177/1099636210385285.

[9] O.B. Olurin, M. Arnold, C. Körner, R.F. Singer, Materials Science and Engineering, A328 (2002) 334.

[10] M. Wicklein, K. Thoma, Materials Science and Engineering, A397 (2005) 391.

[11] P.J. Schilling, B.R. Karedla, A.K. Tatiparthi, M.A. Verges, P.D. Herrington, Composites Science and Technology, 65 (2005) 2071.

[12] K.T. Tan, N. Watanabe, Y. Iwahori, Composites: Part B, 42 (2011) 874.

[13] S.R. Reid, G. Zhou, Impact behaviour of fibre-reinforced composite materials and structures, Edited by CRC Press, (2000).

[14] G. Zhou, Composites Science and Technology, 54 (3) (1995) 267. 